(c) American Dairy Science Association, 2004.

\title{
Study of the Lactation Curve in Dairy Cattle on Farms in Central Mexico
}

\author{
D. Val-Arreola, ${ }^{1}$ E. Kebreab, ${ }^{2}$ J. Dijkstra, ${ }^{3}$ and J. France $^{2}$ \\ ${ }^{1}$ School of Agriculture, Policy and Development, The University of Reading, \\ Earley Gate, Reading RG6 6AR, United Kingdom \\ ${ }^{2}$ Centre for Nutrition Modelling, Department of Animal and Poultry Science, \\ University of Guelph, Ontario N1G 2W1, Canada \\ ${ }^{3}$ Animal Nutrition Group, Wageningen Institute of Animal Sciences, \\ Wageningen University, Marijkeweg 40, The Netherlands
}

\begin{abstract}
Accurate knowledge of lactation curves has an important relevance to management and research of dairy production systems. A number of equations have been proposed to describe the lactation curve, the most widely applied being the gamma equation. The objective of this work was to compare and evaluate candidate functions for their predictive ability in describing lactation curves from central Mexican dairy cows reared under 2 contrasting management systems. Five equations were considered: Gaines (exponential decay), Wood (gamma equation), Rook (Michaelis-Menten $\times$ exponential), and 2 more mechanistic ones (Dijkstra and Pollott). A database consisting of 701 and 1283 records of cows in small-scale and intensive systems, respectively, was used in the analysis. Before analysis, the database was divided into 6 groups representing first, second, and third and higher parity cows in both systems. In all cases except second and above parity cows in small-scale systems, all models improved on the Gaines equation. The Wood equation explained much of the variation, but its parameters do not have direct biological interpretation. Although the Rook equation fitted the data well, some of the parameter estimates were not significant. The Dijkstra equation consistently gave better predictions, and its parameters were usually statistically significant and lend themselves to physiological interpretation. As such, the differences between systems and parity could be explained due to variations in theoretical initial milk production at parturition, specific rates of secretory cell proliferation and death, and rate of decay, all of which are parameters in the model. The Pollott equation, although containing the most biology, was found to be over-parameterized and resulted in nonsignificant parameter esti-
\end{abstract}

Received June 24, 2004.

Accepted July 19, 2004.

Corresponding author: E. Kebreab; email: ekebreab@uoguelph.ca. mates. For central Mexican dairy cows, the Dijkstra equation was the best option to use in describing the lactation curve.

(Key words: modeling, Mexico, small-scale dairy system, lactation curve)

Abbreviation key: BIC = Bayesian information criteria, $\mathbf{M S P E}=$ mean square prediction error, RMSPE $=$ root mean square prediction error.

\section{INTRODUCTION}

Accurate description of a lactation curve is relevant to activities such as conducting feeding trials with lactating cattle, estimating total lactational yield from incomplete records, and forecasting herd performance on a monthly or individual cow basis (Sauvant, 1988). The lactation curve is influenced by 2 interdependent processes, representing the activities of cell growth and death (Dijkstra et al., 1997; Thornley and France, 2005). Hence, when parametric functions are used as mathematical models to describe the lactation curve, a multiplicative form is usually adopted (Dhanoa and Le Du, 1982; Morant and Gnanasakthy, 1989; Rook et al., 1993).

Only a few studies of the lactation curve in Mexican cattle have been conducted, using information from tropical grazing systems (Galaviz-Rodriguez et al., 1998; Ramírez-Valverde et al., 1998a,b) and from dairy systems (Hernandez and Ríos, 1993; González et al., 1997; Salas, 1998). With Holstein-Friesian cows from small-scale dairy enterprises, Salas (1998) found the lactation curve did not show a peak; instead, it decreased steadily from day of calving. Similar results were reported by Ramírez-Valverde et al. (1998b), who found that about $30 \%$ of the curves examined showed a smoothly declining shape. The study by Hernandez and Ríos (1993) with Holstein cows from intensive dairy herds showed a peak and found that the Wood equation gave a good fit with reasonably small standard errors. 
Table 1. Summary statistics for the data on daily milk yield $(\mathrm{kg} / \mathrm{d})$ used in the study.

\begin{tabular}{llllll}
\hline & & \multicolumn{4}{c}{ Statistics } \\
\cline { 3 - 6 } System & & Minimum & Maximum & Mean & $\begin{array}{c}\text { Standard } \\
\text { deviation }\end{array}$ \\
\hline Small-scale & Parity & 4.42 & 19.59 & 13.49 & 3.24 \\
& 1 & 7.78 & 19.49 & 13.33 & 2.26 \\
Intensive & 2 & 2.81 & 19.93 & 13.04 & 2.97 \\
& 3 & 13.36 & 25.02 & 19.02 & 2.69 \\
& 1 & 2.18 & 30.98 & 20.64 & 5.80 \\
& 2 & 1.29 & 33.52 & 20.41 & 6.77 \\
\hline
\end{tabular}

Galaviz-Rodriguez et al. (1998) found an early peak (5.5 wk) and then a steady decline in Brown Swiss cattle.

Various models describing the lactation curve in dairy cows have been reported in the literature, but their practical use under tropical conditions has been limited. The objective of this paper is therefore 1) to collate data from small-scale and intensive dairy units in central Mexico, 2) to select mathematical equations from the literature representing various types of models and subject collated data to analysis, and 3) to determine the most suitable equation or set of equations that describes the lactation curve and explains observed differences in milk yield between contrasting management systems and parity.

\section{MATERIALS AND METHODS}

\section{Data Sources}

A database was constructed using 701 records from small-scale dairy herds between September 1999 and January 2001, and 1283 records from intensive dairy herds between January 1989 and January 2001 in Michoacán State, Mexico. For each management system, the data were sorted according to parity of the cows: (1) first lactation, (2) second lactation, and (3) third or subsequent lactations. The average milk yield per lactation and milk yield after $305 \mathrm{~d}$ were 3746 and 3587 $\mathrm{kg}$ for small-scale and 7543 and $7106 \mathrm{~kg}$ for intensive systems, respectively. The calving interval was 415 and $387 \mathrm{~d}$ for small-scale and intensive systems, respectively. Main characteristics of the 2 systems with respect to daily milk yield are shown in Table 1.

About $40 \%$ of variation comes from seasonal calving effects (Lee, 1973; Mao et al., 1973; Lofgren et al., 1985). To establish a common basis, the data were adjusted according to month of calving. The equation used to estimate the adjustment was that given by Sadek and Freeman (1992):

$$
F_{i}=\left(\mu+x_{r}\right) /\left(\mu+x_{i}\right)
$$

where $F_{i}$ is the multiplicative factor for month $i, \mu$ is overall average milk yield, $x_{r}$ is average milk yield in March (the month of reference), $x_{i}$ is the average milk yield for the month that has to be adjusted. March was considered the month of reference because it was the most uniform. Records were then adjusted as if all the cows had calved in March.

\section{Lactation Equations}

Five equations that have been used to describe the lactation curve and representing empirical and more mechanistic types of models of varying levels of complexity were compared (Table 2). The first equation was a simple 2-parameter model of exponential decay, which was an early attempt to model the lactation curve by Gaines in 1927 (Thornley and France, 2005). The model takes no account of a rise to peak yield after calving. Wood (1967) proposed the widely applied gamma equation, which consists of 3 parameters and takes account of rise to peak. The third equation was from Rook et al. (1993), who explicitly represented the lactation curve as a multiplicative mixture of growth and death processes. After evaluating various functions, they concluded the Mitscherich $\times$ exponential equation fitted their data better than the Wood equation. However, for our data, the Michaelis-Menten $\times$ exponential equation (which

Table 2. Equations used to describe the lactation curve of dairy cows managed under small-scale and intensive systems in central Mexico.

\begin{tabular}{lll}
\hline Equation & Functional form ${ }^{1}$ \\
\hline Gaines & $Y=a \mathrm{e}^{-b t}$ \\
Wood & $Y=a t^{b} \mathrm{e}^{-c t}$ \\
Rook & $Y=a\{1 /[1+b /(c+t)]\} \mathrm{e}^{-d t}$ \\
Dijkstra & $Y=a \exp \left[b\left(1-\mathrm{e}^{-c t}\right) / c-d t\right]$ \\
Pollott & $Y=a\left[1 /\left(1+\frac{1-b}{b} \mathrm{e}^{-c t}\right)-1 /\left(1+\frac{1-d}{d} \mathrm{e}^{-g t}\right)\right]\left(1-\mathrm{e}^{-h t}\right)$ \\
\hline
\end{tabular}

${ }^{1} Y$ is milk yield (kg/d), $t$ is time of lactation (d), and $a, b, c, d, g, h$ $($ all $>0$ ) are parameters that define the scale and shape of the curve. 
has 4 parameters) was superior to the other models of Rook et al. (1993) and was also reported to fit their whole-lactation data well. The fourth and fifth equations were from mechanistic models of the mammary gland by Dijkstra et al. (1997) and Pollott (2000), respectively. The Dijkstra model is based on a set of differential equations representing cell proliferation and cell death in the mammary gland and yields a simple 4parameter algebraic equation. The Pollott model represents 3 processes in the mammary gland, namely cell differentiation and death, and milk secretion rate per cell (Pollott, 2000). The multiplicative form of the model solution (which has 6 parameters) was used in our study.

\section{Statistical Analyses}

Statistical analyses were performed by pooling the data in each category and using the nonlinear mixed procedure (PROC NLMIXED) of SAS (SAS, 2000). The data from small-scale management systems included data gathered from different herds; therefore, it was necessary to consider herd effect not only as fixed but also as random (as the herds represent a random sample from a larger population of herds). Performance of the models was evaluated using the significance level of the parameters estimated, variance of error estimate, and its standard error. Comparison of models used Bayesian information criteria (BIC) (Leonard and $\mathrm{Hsu}$, 2001). Bayesian information criteria are model-order selection criteria based on parsimony and impose a penalty on more complicated models for inclusion of additional parameters. Bayesian information criteria combine the maximum likelihood (data fitting) and the choice of model by penalizing the (log) maximum likelihood with a term related to model complexity as follows:

$$
\mathrm{BIC}=-2 \log (\hat{J})+K \log (N),
$$

where $\hat{J}$ is the maximum likelihood, $K$ is the number of independent parameters in the model, and $N$ is the sample size. A smaller numerical value of BIC indicates a better fit when comparing models. In addition, the observed values of milk output were compared with model predictions. An assessment of the error of predicted relative to observed values was made by calculation of the mean square prediction error (MSPE):

$$
\operatorname{MSPE}=\sum_{i=1}^{n}\left(O_{i}-P_{i}\right)^{2} / n
$$

where $i=1,2, \ldots n, n$ is the number of experimental observations, and $O_{i}$ and $P_{i}$ are the observed and predicted values, respectively. The MSPE was decomposed into error due to the overall bias of prediction, error due to deviation of the regression slope from unity, and error due to disturbance or random variation (Bibby and Toutenburg, 1977). Root MSPE (RMSPE) and the RMSPE expressed as a percentage of the observed mean were used as a measure of the prediction error.

\section{RESULTS}

\section{Cows in Small-Scale Systems}

Figures 1 to 3 show the fit of each model to the data on milk production and DIM. The results indicate that different models can be fitted to the data without difficulty using nonlinear regression. Tables 3 and 4 summarize the key statistical measures used to compare performance of the models. Each model was evaluated separately for first, second, and third or higher parities. For first-lactation cows, the Dijkstra equation performed best, with the lowest BIC (Table 3). All models improved significantly on prediction by the simplest equation (Gaines). However, one parameter estimate for the Rook equation and 4 for the Pollott were not statistically significant. In all the models, the random error component of MSPE was around 99.9\% and RMSPE as a percentage of the observed mean declined from 15.8 in Gaines equation to 12.1 for the Dijkstra equation, with the other equations showing intermediate values (Table 4).

All models gave similar levels of variance of error in the second lactation group (Table 3). Although the Dijkstra equation gave the lowest BIC, improvement on the Gaines and Wood equations was marginal. Only 2 of the parameter estimates for each model (except Pollott) were statistically significant. The RMSPE values and RMSPE as a percentage of the observed mean also reflected marginal enhancement of prediction by the more complicated models but for the Pollott equation, which showed a decrease in performance compared with the simpler models (Table 4).

Models with more parameters failed to improve on predictions by the 2-parameter Gaines equation when fitted to data from third or above lactations in smallscale dairy systems. The lowest BIC values were from the Dijkstra and Wood equations, with MSPE also showing slight improvement on other models (Table 4). Two of the parameter estimates for each model were statistically significant, except the Dijkstra equation, where a third parameter was also significant (Table 3).

For first-lactation cows, peak lactation was predicted to occur at 51 DIM using the Wood equation and at 66 DIM using the others, except for Gaines, which gives peak lactation at parturition (Figure 1). For secondlactation cows, peak occurred at parturition except with the Pollott equation, which showed peak lactation at 


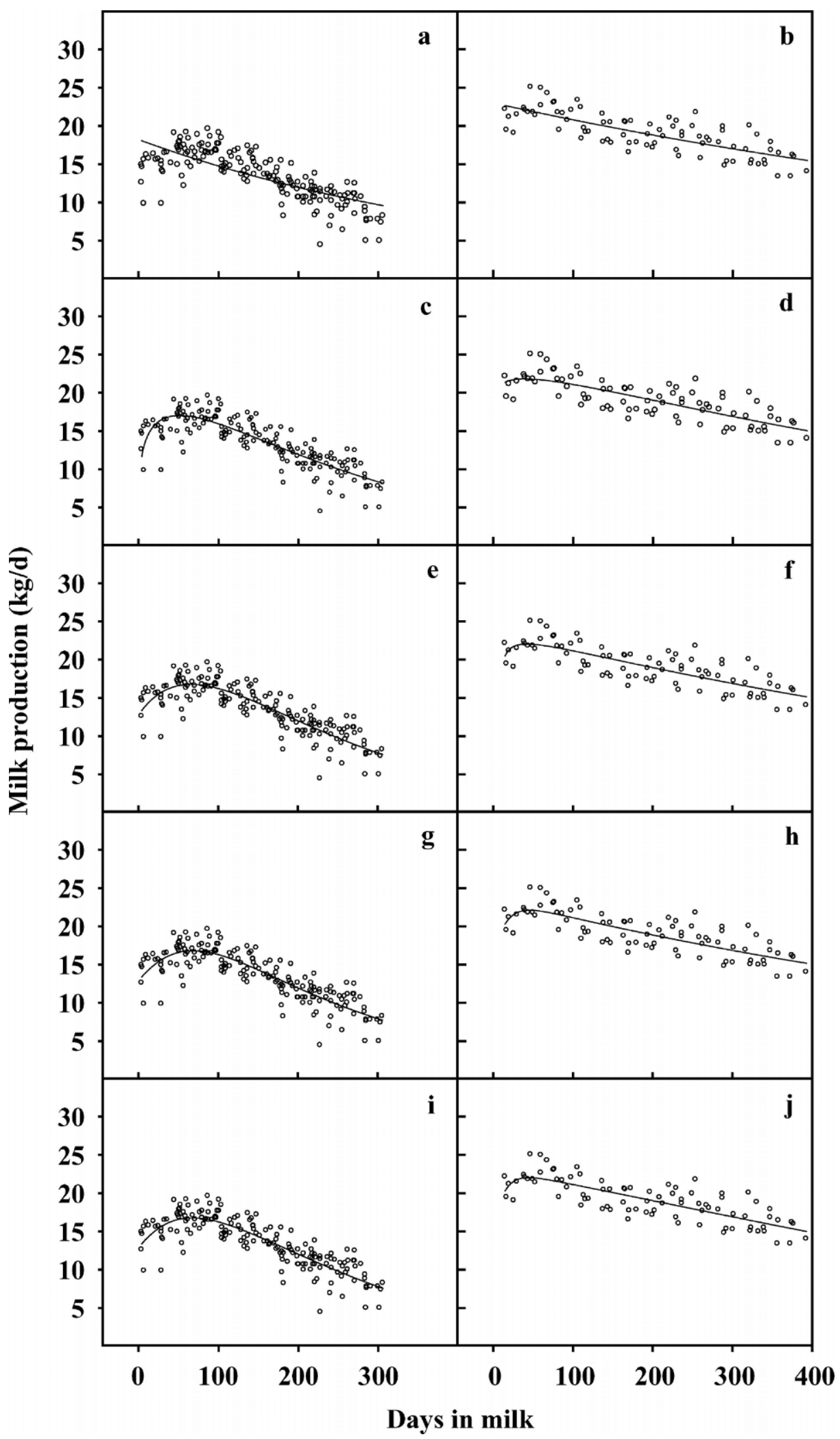

Figure 1. Lactation curves for first-parity cows. Symbols represent observed values. Lines were obtained by fitting the candidate functions: Gaines (a, b), Wood (c, d), Rook (e, f), Dijkstra (g, h), and Pollott (i, j). Cows in small-scale systems are shown in a, c, e, g, and i, while those in intensive systems are shown in $\mathrm{b}, \mathrm{d}, \mathrm{f}, \mathrm{h}$, and $\mathrm{j}$. 


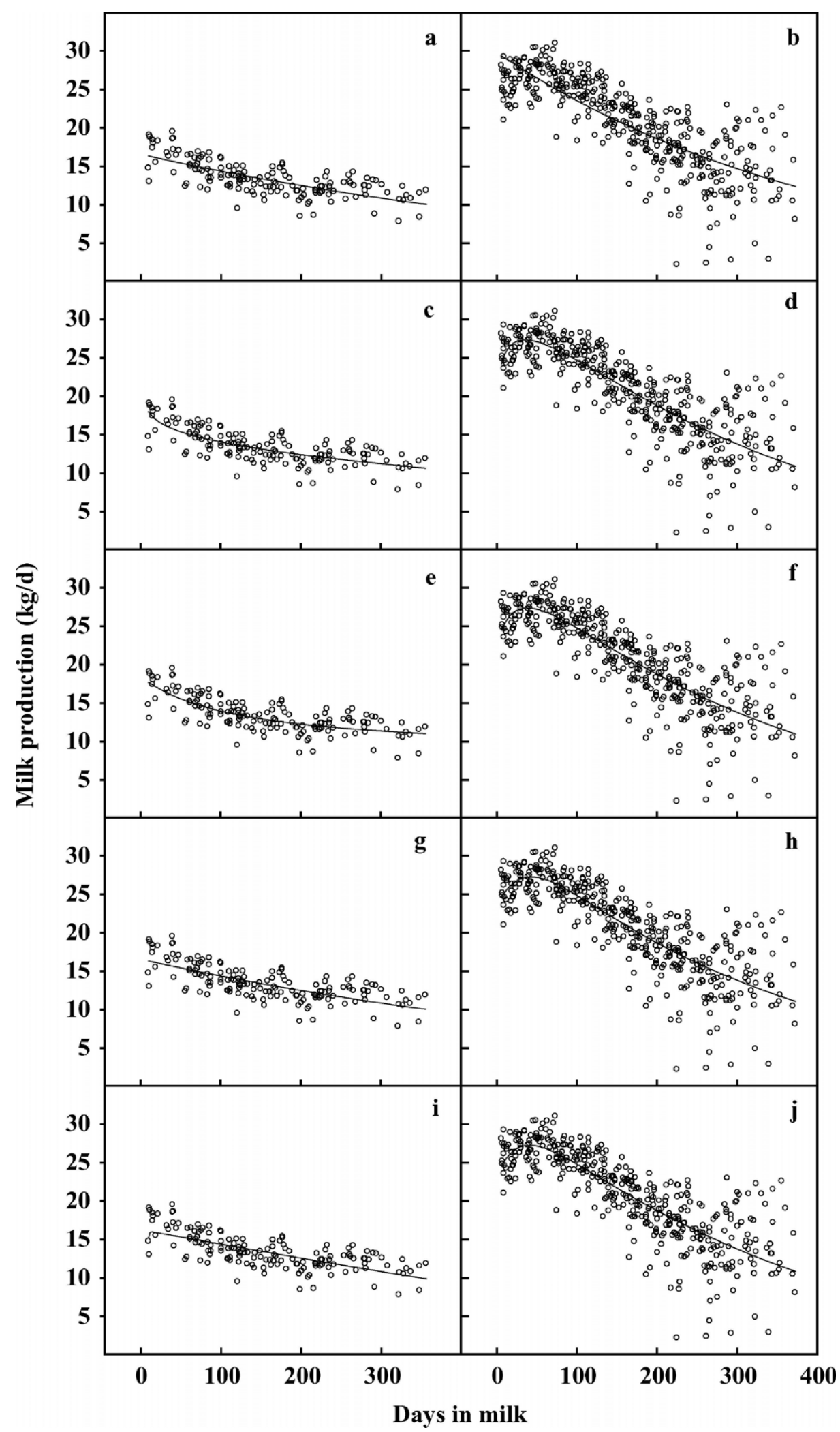

Figure 2. Lactation curves for second-parity cows. Symbols represent observed values. Lines were obtained by fitting the candidate functions: Gaines (a, b), Wood (c, d), Rook (e, f), Dijkstra (g, h) and Pollott (i, j). Cows in small-scale systems are shown in a, c, e, g, and i, while those in intensive systems are shown in $b, d, f, h$, and $j$. 


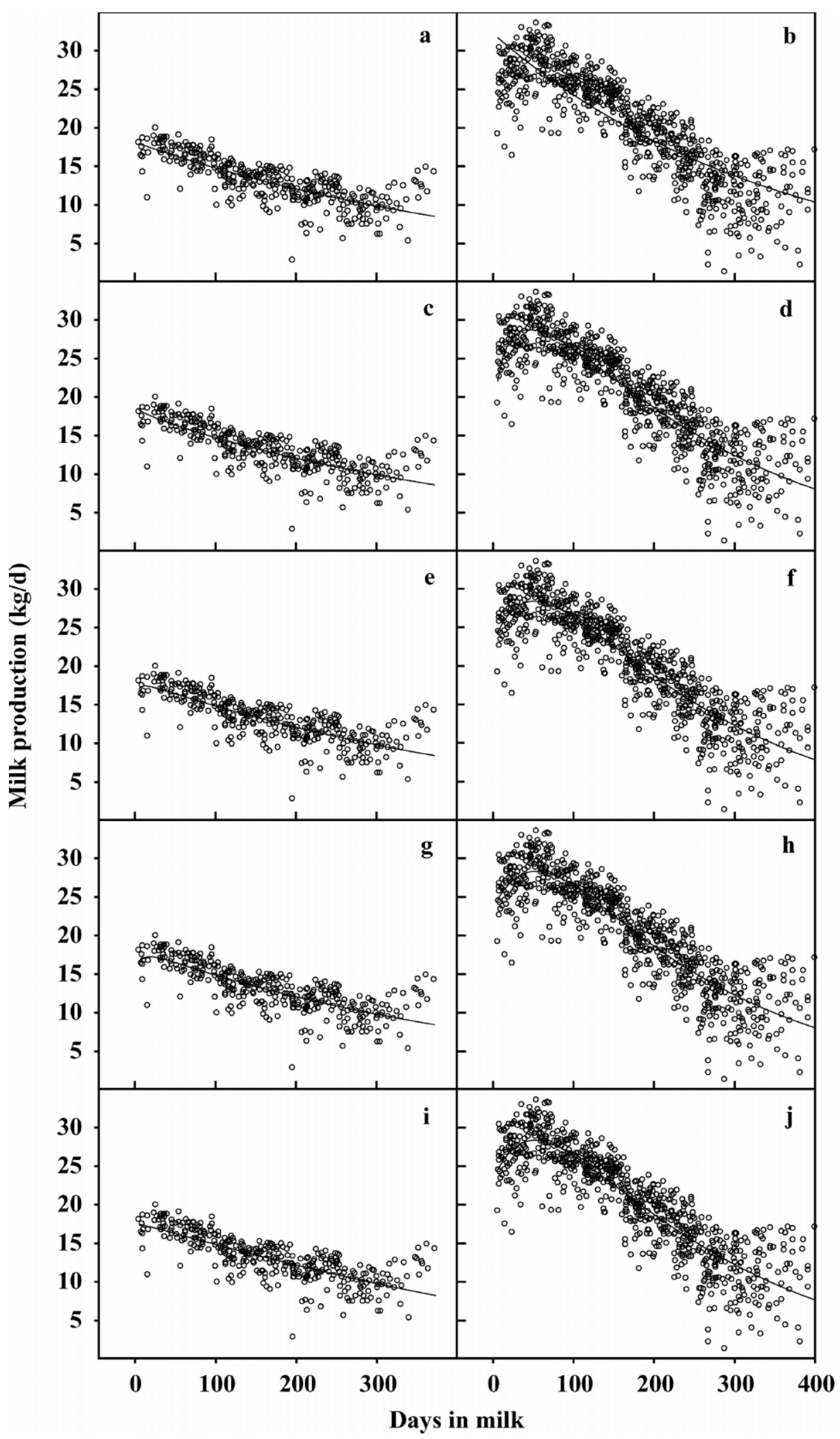

Figure 3. Lactation curves for third- and higher parity cows. Symbols represent observed values. Lines were obtained by fitting the candidate functions: Gaines (a, b), Wood (c, d), Rook (e, f), Dijkstra (g, h) and Pollott (i, j). Cows in small-scale systems are shown in a, c, $\mathrm{e}, \mathrm{g}$, and $\mathrm{i}$, while those in intensive systems are shown in $\mathrm{b}, \mathrm{d}, \mathrm{f}, \mathrm{h}$, and $\mathrm{j}$. 
Table 3. Parameter estimates and other measures when models were fitted to the first-, second-, and third- or higher parity cows in smallscale dairy systems. Standard errors are given in parentheses.

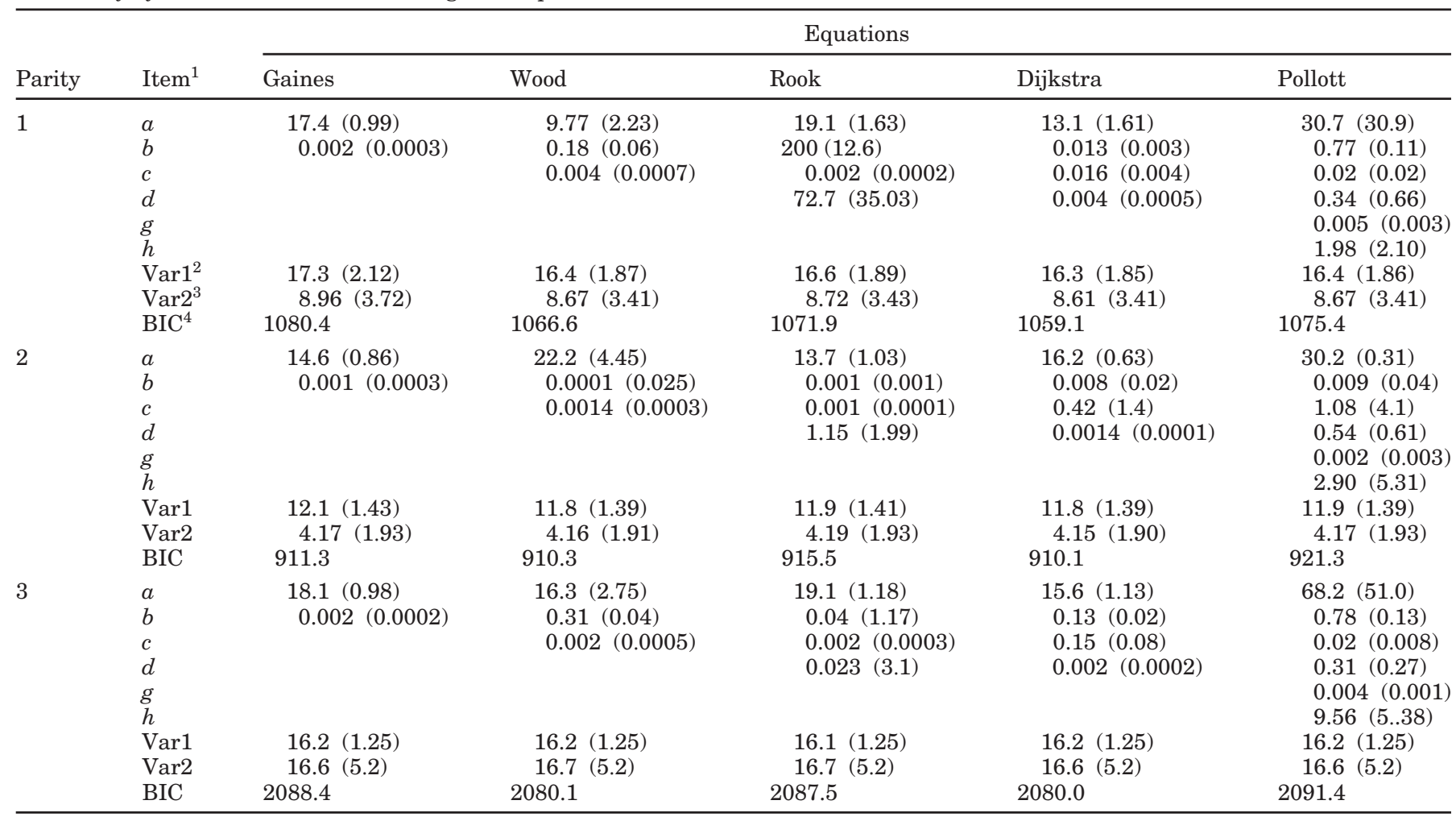

${ }^{1} a, b, c, d, g, h($ all $>0)$ are parameters that define the scale and shape of the curve.

${ }^{2} \operatorname{Var} 1=$ Variance $\left(\sigma^{2}\right)$ of 'error'.

${ }^{3}$ Var2 $=$ Variance $\left(\sigma^{2}\right)$ of herd effects.

${ }^{4} \mathrm{BIC}=$ Bayesian information criteria.

15 DIM (Figure 2). For the cows in the oldest parity group, the Rook and Dijkstra equations predicted peak yield at 16 DIM, while the other models predicted it at parturition (Figure 3).

\section{Cows in Intensive Systems}

Table 5 shows the parameter estimates for the different models fitted for first-, second-, and third-lactation or older cows. For first-lactation animals, parameter estimates for the Gaines, Wood, and Dijkstra equations were all statistically significant, whereas none of the parameter estimates for Pollott and 3 for Rook were significant. There was a reduction in MSPE and in RMSPE as a percentage of the observed mean as model complexity increased, with the lowest values for the Dijkstra equation. All the models gave around 99.9\% of the MSPE as random error (Table 4).

For second-lactation cows, the lowest BIC values were for the Dijkstra equation (Table 5). The more complex models except Pollott gave lower BIC values than Gaines. Root mean square prediction error as a percent- age of the observed mean was reduced from 16.6 for Gaines to 15.5 for Dijkstra (Table 4).

The models that gave better fits for the third-lactation and older cows were the same as for second-lactation cows (Table 5). Parameter estimates were statistically significant for all models except Pollott. The substantial improvement shown by the Dijkstra equation over the simpler models was reflected in MSPE values, and RMSPE as the percentage of the observed mean was reduced from 17.1 for Gaines to 14.6 for Dijkstra (Table 4). All models gave more than 99\% of MSPE as random variation (Table 4).

Predicted time to peak yield for first-lactation cows was similar, ranging from 40 DIM (Wood) to 47 DIM (Dijkstra) except for Gaines, which gives peak yield at parturition (Figure 1). For second-lactation cows, the range in time to peak yield predicted by the models was wider (39 DIM for Rook vs. 51 DIM for Wood) (Figure 2 ). For the cows in the oldest parity group, time to peak yield was predicted to be 46 DIM for Wood, 52 DIM for Rook and Pollott, and 56 DIM for Dijkstra (Figure 3). 
Table 4. Comparison of model performance using mean square prediction error (MSPE), root MSPE (RMSPE), and RMPSE as a percentage of the observed mean (\%RMSPE).

\begin{tabular}{|c|c|c|c|c|c|c|}
\hline \multirow[b]{2}{*}{ Parity } & \multirow[b]{2}{*}{ System } & \multirow[b]{2}{*}{ Equation } & \multicolumn{4}{|c|}{ Model performance } \\
\hline & & & MSPE & RMSPE & $\%$ RMSPE & $\begin{array}{l}\% \text { Random } \\
\text { error }\end{array}$ \\
\hline \multirow[t]{5}{*}{1} & \multirow[t]{5}{*}{ Small-scale } & Gaines & 4.549 & 2.133 & 15.81 & 99.79 \\
\hline & & Wood & 2.951 & 1.718 & 12.73 & 99.99 \\
\hline & & Rook & 2.743 & 1.656 & 12.27 & 99.99 \\
\hline & & Dijkstra & 2.723 & 1.650 & 12.13 & 99.99 \\
\hline & & Pollott & 2.739 & 1.655 & 12.26 & 99.99 \\
\hline \multirow[t]{5}{*}{2} & \multirow[t]{5}{*}{ Small-scale } & Gaines & 2.465 & 1.570 & 11.78 & 99.96 \\
\hline & & Wood & 2.306 & 1.519 & 11.39 & 99.99 \\
\hline & & Rook & 2.219 & 1.489 & 11.78 & 99.92 \\
\hline & & Dijkstra & 2.465 & 1.570 & 11.17 & 99.96 \\
\hline & & Pollott & 2.545 & 1.595 & 11.97 & 99.99 \\
\hline \multirow[t]{5}{*}{3} & \multirow[t]{5}{*}{ Small-scale } & Gaines & 3.524 & 1.877 & 14.40 & 99.96 \\
\hline & & Wood & 3.520 & 1.876 & 14.39 & 99.97 \\
\hline & & Rook & 3.518 & 1.876 & 14.39 & 99.93 \\
\hline & & Dijkstra & 3.501 & 1.871 & 14.31 & 99.94 \\
\hline & & Pollott & 3.620 & 1.903 & 14.59 & 99.96 \\
\hline \multirow[t]{5}{*}{1} & \multirow{5}{*}{ Intensive } & Gaines & 2.878 & 1.697 & 8.92 & 99.99 \\
\hline & & Wood & 2.769 & 1.664 & 8.75 & 99.99 \\
\hline & & Rook & 2.719 & 1.649 & 8.67 & 99.99 \\
\hline & & Dijkstra & 2.677 & 1.636 & 8.50 & 99.94 \\
\hline & & Pollott & 2.697 & 1.642 & 8.63 & 99.94 \\
\hline \multirow[t]{5}{*}{2} & \multirow[t]{5}{*}{ Intensive } & Gaines & 11.712 & 3.422 & 16.58 & 99.97 \\
\hline & & Wood & 10.544 & 3.247 & 15.73 & 99.97 \\
\hline & & Rook & 10.473 & 3.236 & 15.68 & 99.96 \\
\hline & & Dijkstra & 10.378 & 3.222 & 15.51 & 99.98 \\
\hline & & Pollott & 10.475 & 3.237 & 15.68 & 99.97 \\
\hline \multirow[t]{5}{*}{3} & \multirow[t]{5}{*}{ Intensive } & Gaines & 12.131 & 3.483 & 17.07 & 99.71 \\
\hline & & Wood & 9.039 & 3.006 & 14.73 & 99.99 \\
\hline & & Rook & 8.936 & 2.989 & 14.65 & 99.98 \\
\hline & & Dijkstra & 8.897 & 2.983 & 14.62 & 99.99 \\
\hline & & Pollott & 8.963 & 2.994 & 14.67 & 99.97 \\
\hline
\end{tabular}

\section{DISCUSSION}

Empirical and more mechanistic models of the lactation curve of varying complexity have been reported in the literature. Five equations representing different complexity were evaluated using data collected from Mexican dairy herds under 2 contrasting production systems. Comparison of their predictive ability allows identification of a mathematical model capable of describing and providing a better perspective on the shape of the lactation curve of Mexican dairy cows.

The shape of the lactation curve has been shown to be affected by parity, mainly due to a less well-defined peak (related to high variability at the beginning of lactation) and greater persistency in first-lactation cows (Lennox et al., 1992; Sherchand et al., 1995; Scott et al., 1996). Although the shape of the lactation curve showed differences between lactations for both systems, it was more pronounced for small-scale dairy systems. Differences were more related to the presence or absence of peak of production than to a more gradual decline in second and higher lactations. Gradual decline in the lactation curve has been reported by Salas (1998) and Ramírez-Valverde et al. (1998b) on small-scale dairy and tropical dual-purpose systems, respectively. Several studies have shown differences in the general shape of the lactation curve (e.g., Ferris et al., 1985; Pérochon et al., 1996; Ramírez-Valverde et al., 1998b; Landete-Castillejos and Gallego, 2000), the most common shape being a rapid increase after calving to a peak a few weeks later followed by a gradual decline until the cow is dried off. The other shape is a gradual decline from parturition.

All models fitted the data better than the Gaines equation except for those data pertaining to secondand third-lactation cows in small-scale systems. This is due to the absence of a well-defined lactation peak, and therefore the 2-parameter model gave as good a fit as the other candidates. In general, the Wood equation gave a similar goodness of fit as Rook. The additional parameter in the Rook equation appears to have caused some of the estimates to be nonsignificant, especially when a weak peak of lactation is observed. Among the models that improved on Gaines, the Dijkstra equation stands out as consistently outperforming the others 
Table 5. Parameter estimates and other measures when models were fitted to the first-, second-, and third- or higher parity cows in intensive dairy systems. Standard errors are given in parentheses.

\begin{tabular}{|c|c|c|c|c|c|c|}
\hline Parity & Item $^{1}$ & \multicolumn{5}{|c|}{ Equations } \\
\hline 1 & $\begin{array}{l}a \\
b \\
c \\
d \\
g \\
h \\
\operatorname{Var}^{2} \\
\text { BIC }^{3}\end{array}$ & $\begin{array}{l}23.6(0.59) \\
0.001(0.0001)\end{array}$ & $\begin{array}{l}12.6(1.96) \\
0.17(0.04) \\
0.002(0.0003)\end{array}$ & $\begin{array}{l}27.9(1.39) \\
210(12.8) \\
0.002(0.0002) \\
29.7(9.08)\end{array}$ & $\begin{array}{c}17.1(3.01) \\
0.012(0.001) \\
0.027(0.001) \\
0.002(0.0003)\end{array}$ & $\begin{array}{c}31.9(40.1) \\
0.74(0.29) \\
0.044(0.059) \\
0.23(0.81) \\
0.004(0.006) \\
27.1(81.3) \\
4.65(0.76) \\
396.3\end{array}$ \\
\hline 2 & $\begin{array}{l}a \\
b \\
c \\
d \\
g \\
h \\
\text { Var1 } \\
\text { BIC }\end{array}$ & $\begin{array}{l}31.2(0.63) \\
0.002(0.0001)\end{array}$ & $\begin{array}{l}19.1(1.93) \\
0.15(0.03) \\
0.004(0.0003)\end{array}$ & $\begin{array}{l}35.5(1.3) \\
24.1(0.57) \\
0.003(0.0002) \\
7.28(1.88)\end{array}$ & $\begin{array}{l}25.4(1.76) \\
0.009(0.003) \\
0.02(0.01) \\
0.004(0.0005)\end{array}$ & $\begin{array}{c}89.9(0.01) \\
0.89(0.02) \\
0.03(0.01) \\
0.61(0.024) \\
0.004(0.0004) \\
2.91(27.1) \\
26.3(1.95) \\
2576.9\end{array}$ \\
\hline
\end{tabular}

when BIC values were considered. Although the Rook and Dijkstra equations have the same amount of parameters, those of Dijkstra are physiologically based and were estimated significantly. The mechanistic nature of the model allows deeper insight into causes of differences between the 2 production systems compared and between lactations. Although the Pollott model is also mechanistic, it did not perform as well as Dijkstra. This is because Pollott represents cell differentiation and decline in cell numbers by 2 logistic curves, which increases the parameters to be estimated to 6 . This contributes to an over-parameterized model, hence nonsignificant estimates of up to 4 parameters. Pollott (2000) suggested that his model is likely to require a reduction in the number of parameters describing the lactation curve. Perhaps the Pollott equation might have performed better had our data contained more information on cell differentiation and death.

The Dijkstra equation helps to tease apart possible underlying reasons for differences in milk yield observed in dairy cows from different systems. The parameter estimate for theoretical initial milk production $(a)$ was always statistically significant and ranged from 9 to $16 \mathrm{~kg} / \mathrm{d}$ and 17 to $25 \mathrm{~kg} / \mathrm{d}$ for small-scale and intensive systems, respectively. This explains one of the main differences in the 2 systems. Furthermore, estimates of parameter $a$ were lower for primiparous cows than for second- and third-parity cows, which showed similar estimates. Comparison of parameter estimates for firstparity cows reveals the specific rate of secretory cell proliferation (b) for cows in intensive systems was similar to those in small-scale systems. The decay parameter (c) was almost double for intensively managed cows (0.027/d vs. 0.016/d for cows in intensive and smallscale systems). This is consistent with the observations of Dijkstra et al. (1997) that high values of the decay parameter are related to rapidly occurring, sharp peaks in milk production. The specific rate of cell death $(d)$ was 2 times higher for cows in small-scale systems, indicating a more rapid decline after peak lactation, which is evident from Figure 1.

The lactation curves for second and higher parity cows in small-scale systems showed only gradual decline, and the empirical models described the curves as good as the more mechanistic ones. Pérochon et al. (1996) and Landete-Castillejos and Gallego (2000) also reported empirical models were effective in describing the curve. Dijkstra et al. (1997) stated that their equation did not improve on the Wood equation when the lactation curve was a gradual decline from parturition 
because the number of cells and the enzymatic activity per cell in the mammary gland cannot both be defined uniquely from lactation data. With second and above parity cows in small-scale systems, the gentle slope of the lactation curve caused the cell proliferation and decay parameters to be nonsignificant as discussed above. However, the parameter estimate for specific rate of cell death was significant and was 2 or 3 times higher for cows in intensive systems than in small-scale systems, which is an accurate representation of the data (Figures 2 and 3). As Cobby and Le Du (1978) suggested, perhaps 2 main reasons for observing a curve with no peak could be peak yield being achieved soon after calving and not enough data are available, which leads to lack of statistical significance of parameter estimates. Another suggestion is the secretory cell population might already be in a declining phase at parturition (Rook et al., 1993).

Cow-to-cow variation in milk production could be due to the animal (parity, pregnancy, or health) or the environment (calving season, management practices, and health) (Lennox et al., 1992; Sherchand et al., 1995; Pérochon et al., 1996). However, for the multiparous cows intensively managed, there was high variability at the end of the lactation producing a nonconstant variance that might be related to pregnancy effects, which for primiparous cows is independent of milk yield (Pérochon et al., 1996).

The Gaines equation is simplistic and does not provide a physiological basis for the lactation curve. For the data used in the study, the Wood equation was better than Gaines, as it gave lower BIC and most of the parameter estimates were significant. Although the Rook equation explained more of the variation compared with Gaines and Wood, some of its parameter estimates were not always statistically significant. Despite the Pollott equation having a mechanistic basis, we found that in the Mexican context and for the data available, the parameter requirements were too detailed. In spite of variability, adjustment methods, and quality of information, which is sometimes limited in the case of Mexican dairy herds, the Dijkstra equation appears to be the preferred option to apply to different types of systems. It also has an added advantage that it is relatively easy to calculate total milk yield at the end of lactation.

\section{ACKNOWLEDGMENTS}

The authors thank Manuel Jaime Tena Martinez for providing records from his dairy herd and for comments. We also wish to thank Rafael Tzintzun Rascon from Universidad Michoacana de San Nicolás de Hidalgo, for providing information generated by his exten- sion and research program on small-scale dairy herds at Pátzcuaro and Alváro Obregón in Michoacán State and to the National Council of Science and Technology (CONACYT) for sponsoring this work.

\section{REFERENCES}

Bibby, J., and H. Toutenburg. 1977. Prediction and Improved Estimation in Linear Models. John Wiley and Sons, London, UK.

Cobby, J. M., and L. P. Le Du. 1978. On fitting curves to lactation data. Anim. Prod. 26:127-133.

Dhanoa, M. S., and Y. L. P. Le Du. 1982. A partial adjustment model to describe the lactation curve of a dairy cow. Anim. Prod. 34:243-247.

Dijkstra, J., J. France, M. S. Dhanoa, J. A. Maas, M. D. Hanigan, A. S. Rook, and D. E. Beever. 1997. A model to describe growth patterns of the mammary gland during pregnancy and lactation. J. Dairy Sci. 80:2340-2354.

Ferris, T. A., I. L. Mao, and C. R. Anderson. 1985. Selecting for lactation curve and milk yield in dairy cattle. J. Dairy Sci. 68:1438-1448.

Galaviz-Rodriguez, J. R., C. G. Vazquez-Pelaez, J. Ruíz-López, F. Lagunes-Lagunes, R. Claderon-Robles, and J. Rosete-Hernandez. 1998. Environmental factors that affect the lactation curve of Brown Swiss cows in subtropical climates. Técnica Pecuaria Mexico 36:163-171. (Abstr.)

González, L. G., S. E. A. Esperon, and O. R. S. Gomez. 1997. Development of the productive capacity of low-income farmers and smallscale dairy production in rural communities and poor urban areas. Pages 17-20 in Proc. Small-Scale Dairy Systems Symp. Centre of Agric. Res., Fac. Vet. Medicine, Mexico State Autonomous Univ., Toluca, Mexico.

Hernández, Q. J. J., and R. J. C. Rios. 1993. Comparison between incomplete gamma and linear gamma equations used to describe the shape of the lactation curve. Pages 11-19 in Proc. 14th Ampa Meeting, Fac. Anim. Sci., Chihuahua Autonomous University, Mexico.

Landete-Castillejos, T., and L. Gallego. 2000. The ability of mathematical models to describe the shape of lactation curves. J. Anim. Sci. 78:3010-3013.

Lee, A. J. 1973. Month, year, and herds effects on age adjustment of first lactation milk yield. J. Dairy Sci. 57:332-338.

Lennox, S. D., E. A. Goodall, and C. S. Mayne. 1992. A mathematical model of the lactation curve of the dairy cow to incorporate metabolizable energy intake. Statistician 41:285-293.

Leonard, T., and J. S. J. Hsu. 2001. Bayesian Methods. Cambridge Univ. Press, Cambridge, United Kingdom.

Lofgren, D. L., W. E. Vinson, R. E. Pearson, and R. L. Powell. 1985. Adjustments to cow indexes for milk yield for effects of herd mean and standard deviation. J. Dairy Sci. 68:3301-3311.

Mao, I. L., J. W. Wilton, and E. B. Burnside. 1973. Parity in age adjustment for milk and fat yield. J. Dairy Sci. 57:100-104.

Morant, S., and V. A. Gnanasakthy. 1989. A new approach to the mathematical formulation of lactation curves. Anim. Prod. 49:151-162.

Pérochon, L., J. B. Coulon, and F. Lescourret. 1996. Modelling lactation curves of dairy cows with emphasis on individual variability. Anim. Prod. 63:189-200.

Pollott, G. E. 2000. A biological approach to lactation curve analysis for milk yield. J. Dairy Sci. 83:2448-2458.

Ramírez-Valverde, R., G. Ramírez-Valverde, R. Núñez-Dominguez, and A. Tewolde-Medhin. 1998a. Lactation curves of Angus, Brown Swiss and crossbred cows: I. Comparison of procedures for estimating parameters. Agrociencia 32:317-323.

Ramírez-Valverde, R., G. Ramírez-Valverde, R. Núñez-Dominguez, and A. Tewolde-Medhin. 1998b. Lactation curves of Angus, Brown Swiss and crossbred cows: II. Comparison of equations. Agrociencia 32:325-330.

Rook, A. J., J. France, and M. S. Dhanoa. 1993. On the mathematical description of lactation curves. J. Agric. Sci. 121:97-102. 
Sadek, M. H., and A. E. Freeman. 1992. Adjustment factors for previous and present days open considering all lactations. J. Dairy Sci. 75:279-287.

Salas, R. G. 1998. Re-initiation of the post-partum ovary activity in Holstein cows in small-scale dairy herds. M.Sc. Thesis, Univ. Michoacán State, Morelia, México.

SAS User's Guide. Statistics, Version 8 Edition. 2000. SAS Inst., Inc., Cary, NC.

Sauvant, D. 1988. Modelling of lactation and nutrition. Pages 149155 in Korver S., and J. A. M. Van Arendonk, ed. Modelling of Livestock Production Systems. Kluwer Academic Publishers, Dordrecht, The Netherlands.
Scott, T. A., B. Yandell, L. Zepeda, R. D. Shaver, and T. R. Smith. 1996. Use of lactation curves for analyzing of milk production data. J. Dairy Sci. 79:1885-1894.

Sherchand, L., R. W. McNew, D. W. Kellog, and Z. B. Johnson. 1995. Selection of a mathematical model to generate lactation curves using daily milk yields of Holstein cows. J. Dairy Sci. 78:25072513.

Thornley, J. H. M., and J. France. 2005. Mathematical Models in Agriculture: Quantitative Methods for the Plant and Animal Sciences. 2nd ed. CAB International, Wallingford, UK.

Wood, P. D. P. 1967. Algebraic model of the lactation curve in the cattle. Nature (Lond.) 216:164-165. 